Makale Geliş | Received: 19.09.2019

Makale Kabul | Accepted: 04.10.2019

DOI: $10.18795 /$ gumusmaviatlas.622245

Mavi Atlas, 7(2)/2019: 265-274

Araştırma Makalesi | Research Article

\author{
Mustafa ÖZYÜREK \\ Dr. Öğr. Üyesi| Assist. Prof. Dr. \\ Iğdır Üniversitesi, Fen-Edebiyat Fakültesi, Tarih Bölümü, Iğdır, TÜRKIYYE \\ Igdir University, Faculty of Science and Letters, Department of History, Igdir, TURKEY \\ ORCID: 000-0001-5426-9775 \\ mozyurek25@gmail.com
}

\title{
Türkiye Cumhuriyeti’nin İlk Maliye Bakanı Gümüşhane Milletvekili Hasan Fehmi Ataç'ın Mali Alandaki Faaliyetleri
}

$\ddot{O} \mathbf{z}$

1879'da Gümüşhane'de doğan Hasan Fehmi Bey, başladığı ilk ve orta öğrenimini İstanbul'da tamamlamıştır. Çeşitli görevlerde bulunduktan sonra Osmanlı Mebusan Meclisinde 18 Nisan 1912-5 Ağustos 1912 ile 15 Şubat 1913-21 Aralık 1918 tarihleri arasında iki dönem Gümüşhane mebusluğu yapmıştır. Daha sonra Ankara’ya geçerek Mustafa Kemal Paşa'nın yanında Millî Mücadeleye katılmıştır. Türk siyasi hayatında çok önemli bir yere sahip olan Hasan Fehmi Ataç'ın en önemli hizmeti kuşkusuz Millî Mücadele Dönemi’nde 19 Mayıs 1921-9 Temmuz 1922 tarihleri arasında yaptığı maliye vekilliğidir. Çünkü devletin kısıtlı gelirlerine rağmen Türk ordusunun hemen hemen bütün ihtiyaçlarını karşılamayı başarmıştır. Doğu ve Batı orduları için iki ayrı defterdarlık kurarak subay maaşlarının düzenli olarak ödenmesini sağlamış, ayrıca Büyük Taarruz’un finans kaynaklarını temin ve organize etmiştir. Hasan Fehmi Bey, Türkiye Büyük Millet Meclisinin açılmasından itibaren ilk sekiz dönem boyunca Gümüşhane milletvekilliği yapmıştır. 1 Kasım 1923-2 Ocak 1924 tarihleri arasında cumhuriyet tarihinin ilk maliye vekilliği görevinde bulunmuş, daha sonra 1924-1925 yıllarında ise ziraat vekilliği yapmıştır. Sonraki yıllarda anayasa, bütçe ve maliye komisyonlarında görev almış ve 1961'de vefat etmiştir.

Anahtar Kelimeler: Gümüşhane, Siyaset, Maliye, Biyografi.

\section{Economic Activities of Gümüşhane Congressman Hasan Fehmi Ataç, the First Finance Minister of Turkey Republic}

\begin{abstract}
Born in 1879 in Gümüşhane, Hasan Fehmi Bey, started his primary and secondary education in Gümüşhane and completed it in Istanbul. After serving in various positions, he served as the deputy of Gümüşhane for two terms in the Ottoman Parliament between 18 April 1912-5 August 1912 and 15 February 1913-21 December 1918. Later, he went to Ankara and joined the National Struggle with Mustafa Kemal Pasha. The most important service of Hasan Fehmi Bey, who has a very important place in Turkish political life, is undoubtedly his Deputy Finance Minister during the National Struggle Period between 19 May 1921-9 July 1922. Because of the limited income of the state, it has managed to meet almost all the needs of the Turkish army. He established two separate registries for the Eastern and Western Armies, ensuring that officers' salaries were paid regularly, and provided and organized the financial resources of the Great Offensive. Hasan Fehmi Ataç has made Gumushane Parliament during the first eight periods, from 1 November 1923 to 2 January 1924, he served as the first deputy of finance in the history of the republic, and later served as Deputy Minister of Agriculture in 1924-1925. In the following years, he served in the constitution, budget and finance commissions and passed away in 1961 .
\end{abstract}

Keywords: Gümüşhane, Policy, Finance, Biography. 


\section{Giriş}

Erzurum-Trabzon karayolu üzerinde bulunan, 7626 kilometre kare yüzölçümü ile denizden 1400 m yükseklikte olan Gümüşhane ili, jeopolitik bakımdan olduğu kadar tarihe kazandırdığı yüksek şahsiyetlerle de büyük önem arz etmektedir (Çetin vd. 1997: 11) "Gümüşhane" ad1, gümüş madeninin bol olması nedeniyle verilmiş olup, sayısı 25 'i bulan bu ocaklardan elde edilen gümüşten darphanelerde sikkeler basılmakta idi. İranTrabzon yolu üzerinde bulunmasının yanı sira bu maden ocaklarının sayesinde Gümüşhane'nin önemi daha da artmış ancak bu durum 19. yüzyıla kadar devam etmiştir. Çünkü Osmanlı-Rus savaşları, halkın buradan göç etmesine ve belirtilen maden ocaklarının işletilmesinin de durmasına neden olmuştur (Cumhuriyetin 50. Yılında Gümüşhane 1973 İl Y1llı̆̆1 1974: 2)

Tanzimat'in ilk yıllarında Erzurum'dan ayrılarak Trabzon eyaletinin bir livası hâline gelen Gümüşhane, Birinci Dünya Savaşı sırasında 19 Temmuz 1916'da Ruslar tarafından işgal edilmiş, Rusların çekilmesinden sonra onların bıraktığı boşluğu dolduran Ermenilerin temizlenmesiyle 28 Şubat 1918'de tamamen harap bir hâlde işgalden kurtarılmıştır. Cumhuriyetin ilanından sonra 20 Nisan 1924'te çıkarılan 491 sayılı Teşkilât-1 Esasiye Kanunu'nun 89. maddesine göre il olmuştur (Sayılarla Gümüşhane: 16)

Gümüşhane tarih boyunca birçok önemli şahsiyet yetiştirmiş olup, bunlardan birisi de Hasan Fehmi (Ataç) Bey’dir. Kendisi, Gümüşhane’de doğmuş ve bölgenin yerlisi olan köklü bir aileye mensuptur. Hasan Fehmi Bey, 21 yıl süreyle Kudüs Valiliği yapan İbrahim Lütfü Paşa'nın torunudur. Ailesi Bayburt'a bağlı Nişantaşı ve Akşar köylerinin Beyi idi. Ailesinin adı olan "Kadirbeyoğlu", Fatih Sultan Mehmet'in silah hocası Gaye Paşa'nın oğlu Kadir Paşa'dan gelmektedir. Hasan Fehmi Bey, Zeki Kadirbeyoğlu ile amca çocukları olup, soyadlarının farklı oluşunun sebebi ise Hasan Fehmi Bey’e "Ataç" soyadının Atatürk tarafından verilmesi ile olmuştur (Dabağ, Sevim 2019: 13)

\section{A. Hasan Fehmi Bey'in Ailesi ve Tahsil Hayatı}

1879 y1lında Gümüşhane'de doğan Hasan Fehmi Bey, Kadirbeyzade Mehmet Salim Efendi ve Mahbure Hanım'ın oğludur. Ailenin ikinci oğlu olarak dünyaya gelmiş, Osman ve Hüseyin adında iki kardeşi daha vardır. İlk ve orta öğrenimini özel öğrenimle tamamlamış, ayrıca iktisat ve maliye eğitimi görmüştür. Daha sonra İstanbul'a giderek Osmanlı Mebusan Meclisinin ikinci dönemi için 5 Mayıs 1912'de yapılan seçimlerde Gümüşhane milletvekili olmuştur. Aynı mecliste üçüncü dönemde de milletvekilliğini 
sürdürdükten sonra meclisin feshedilmesi üzerine memleketine dönmüş ve Millî Mücadeleye katılmıştır. (Çoker 1995: 451, Dabă̆ 2019: 13)

\section{B. Hasan Fehmi Bey’in Millî Mücadeleye Katılması}

Vilâyât-1 Şarkıye Müdâfaayı Hukuk-1 Milliye Cemiyetinin Erzurum şubesi tarafından 23 Temmuz 1919-7 Ağustos 1919 tarihleri arasında yaklaşık 60 kişinin ${ }^{1}$ katılımıyla Erzurum Kongresi toplanmıştı (Konukçu 1989: 128) Kongreye bugünkü Gümüşhane bölgesinden 4 kişi katılmıştır. $\mathrm{Bu}$ kişiler; Gümüşhane'den Kadirbeyoğlulları'ndan Çiftçi Zeki Bey, Bayburt’tan Hazine Vekili Alemdarzâde Teyfik Bey, Bayburt'tan dönemin Belediye Başkanı Abdullah Ağazade Zahit Efendi ve Kelkit’ten Müftü Osman Efendi idi (Cumhuriyetin 50 yılında Gümüşhane 1973 İl Yıllığı: 2)

Hasan Fehmi Bey, İstiklâl Harbi’nde Batı cephesinde gönüllü olarak görev almış ve iç ayaklanmaların bastırılmasında önemli yararlılıklar göstermiştir. Ankara' da Türkiye Büyük Millet Meclisinin açılmasıyla Gümüşhane milletvekili olarak 19 Mayıs 1920'de meclise katılmıştır (TBMM Arşivi, Sicil Dosya No: 187). Mecliste mali kanunlar, iktisat, anayasa ve Sayıştay komisyonlarında görev almış, Kırşehir Milletvekili Cemalettin Efendi'nin 17 Ağustos 1920'de izne ayrılması üzerine bir ara II. Başkan Vekilliği yapmıştır. 2 Mart 1921'de I. Başkan Vekili olmuşsa da 24 Aralık 1921'de istifa etmiştir (Çoker 1995: 451). Ankara Hükümeti Millî Mücadele Dönemi'nde Rusya ile yakın ilişkiler kurmak için Bekir Sami Kunduh ve Yusuf Kemal Tengirşek'in de bulunduğu bir heyeti 11 Mayıs 1920’de Moskova’ya göndermişti. 19 Temmuz 1920'de Moskova'ya ulaşan heyet, Rusya Dış İşleri Bakanı Çiçerin ile bir görüşme yapmıştı. Görüşmede TBMM ile Ermenistan arasında Moskova'nın arabuluculuk yapması kararlaştırılmış ve Türkiye'ye bir yardım heyeti gönderilmişti. Ancak Çiçerin, Van ve Bitlis'te Ermeniler için toprak talebinde bulununca görüşmeler durdurulmuş ve Türk Heyeti, Rusya'nın bu talebini kabul etme yetkisine sahip olmadığını ileri sürerek TBMM'nin fikrini almak üzere Ankara'ya dönmüştü. Heyet dönünce konu TBMM'de görüşülmeye başlanmıştı (TBMM Gizli Celse Zabitları I/I-I: 158-173).

17 Ekim 1920 tarihinde TBMM'de yapılan görüşmelerde Hasan Fehmi Bey de söz almış ve konuyla alakalı düşüncelerini paylaşmıştır. Konuşmasında, I. Dünya Savaşı sonrası Osmanlı Devleti’nin durumu ve Türk milletinin milli gayelerinden bahseden

\footnotetext{
${ }^{1}$ Erzurum Kongresi'ne katılan delegelerin sayısı Kâzım Karabekir Paşa'nın 5 Ağustos 1919'da Harbiye Nezareti'ne gönderdiği telgrafta 70 kişi olarak belirtilmiş, bu sayının Cevat Dursunoğlu 54, Mahmut Goloğlu 56, Mazhar Müfit Kansu 57, M. Fahrettin Kırzıoğlu 72 kişi olduğunu ileri sürmüşlerdir.
} 
Hasan Fehmi Bey, sözü Türk-Rus ilişkilerine getirerek, Bolşevik ihtilali sonrasında Rusya'nın idare tarzında birtakım değişiklikler olmasına rağmen dış politika esaslarının aynen devam ettiğini söylemiştir. Hasan Fehmi Bey, yaklaşık üç yüz elli yıldır mağlup olunan Ruslara karşı Brest-Litowsk Muahedesi'nde elde edilen tek başarı olduğunu belirtmiş, ayrıca Rusya'dan alınan maddi yardıma karşılık Doğu Anadolu'da Ermeniler lehine toprak verilmesi yönündeki Rus talebine şiddetle karşı çıkmıştır. Ona göre Ruslar, Panturanizm ile hareket eden Türk milletine karşı olan millî hislerinden asla vazgeçmemiş ve tarihi emellerini aynen devam ettirmekteydiler (TBMM Gizli Celse Zabitları I/I-I: 176-178).

Millî Mücadele Dönemi’nde, TBMM hükümetlerinin en güç işlerini maliye vekilleri yüklenmişti. Bütçe Komisyonu tarafından arazi vergisi hakkında hazırlanan bir kanun tasarısının 22 Nisan 1922'de mecliste reddedilmesi üzerine Maliye Vekili Hasan (Saka) Bey istifa etmiş, Mustafa Kemal Paşa ise ona "o halde bana maliyeden anlamayan birini bul” demişti. Bunun üzerine ertesi gün M. Kemal Paşa’nın odasına Hasan Fehmi Bey davet edilmişti. Hasan Fehmi Bey'e göre "Osmanlı idaresinde memuriyetlik yapmış kişilerin ruhuna idarenin aczi ve zaafı sinmişti”. Neticede, iki gün sonra yapılan vekillik seçiminde 191 oyun 129'unu alan Hasan Fehmi Bey Maliye Vekili seçilmiştir (Selek 1987: 138, Demirel 2003: 334-335).

\section{Hasan Fehmi Bey’in İlk Maliye Vekilliği ve Büyük Taarruz Öncesi Hazırlıklar}

İstanbul'un 16 Mart 1920'de İtilaf Devletleri tarafından işgali üzerine, Erzurum ve Sivas Kongrelerinde oluşturulan Heyet-i Temsiliye, Anadolu'nun mali kaynaklarına el koymuştu. Ancak memleketin sınırları henüz tam olarak belli olmadığı için Hasan Fehmi Bey ilk olarak, mümkün olan yerlerde gümrük teşkilatı meydana getirmişti (Selek 1987: 136-139). Öte yandan, Sakarya Meydan Muharebesi'nin kazanılmasindan sonra hazırlık dönemine giren Türk ordusunun Yunanlıları Anadolu'dan çıkarabilmesi ancak büyük bir taarruzu başarıya ulaştırmasına bağlı idi. Ancak bunun için de birçok eksiğin tamamlanması, yeteri kadar para bulunabilmesi gerekmekteydi. Büyük Taarruz'un hazırlık dönemi, ciddi ekonomik sıkıntıların yaşandığı dönemdir. Genel seferberliğin ilan edilmesiyle silah altına alınan yaklaşık iki yüz bin kişilik ordunun iaşe ve mühimmat ihtiyaçlarının karşılanması için yeni gelir kaynaklarına ihtiyaç duyulmasına yol açmaktaydı. Bu nedenle Sakarya Meydan Muharebesi'nden bir ay sonra yapılması düşünülen taarruz, gerekli hazırlıkların yapılabilmesi için kıştan sonraya ertelenmişti. Bu süreçte Maliye Bakanı Hasan Fehmi Bey, gelir-gider dengesini kendine has yöntemleriyle 
bulmaya çalışmaktaydı. Onun mali formülü şöyle idi: "Para, yağlı kurşun ve keskin süngüye." Ordu haricindeki kurum ve kuruluşlara ancak günlük elzem ihtiyaçlarını karş1layacak kadar para vermekteydi (Müderrisoğlu 2013: 412-413). Hasan Fehmi Bey, bu süreçte karşılaşılan sorunları şu sözlerle anlatmıştı:

Milli Savunma Bakanlı̆̆ devamlı olarak çarşaf gibi teklifler getiriyordu. Bir defasında 400 bin postal için para istedi. Ben bu parayı versem 400 bin postalı nerede, kime ve ne kadar zamanda yaptıracaksınız, çarık isterseniz aklım erer dedim, teklifi geri aldılar. Bir gün de ordu komutanları çeşitli ihtiyaçlar için on otomobil istedi. Para yerine "istediğiniz otomobilleri Yunanlılar İzmir'de hazırladılar, orada duruyor, gidin bedelsiz alın" dedim. "Ruslardan gelen 300 bin altından on para harcamamıştım. Telgraf başında her yeri sıkıştırarak tahsilat yaptıriyordum. Gelen parayı üzerine ekledim. Ordu defterdarlarından hesap istedim. Baktım ki, bazı birliklerde iki ay, bazılarında dört ay aylık almamış subaylar var. Üç milyon lira alıp Akşehir'e gittim. Aylıkları aynı seviyeye getirecek şekilde dağıtılmak üzere verdim. Sonra üç milyon daha gönderdim. Artarsa ikişer ayın birini, hiç olmazsa yarım aylık dağıtın dedim. Akşehir dönüşünde M. Kemal Paşa'ya ne kadar subay olduğunu, aylık alacaklarının miktarını söyledim. Fevzi Paşa da oradaydı. M. Kemal Paşa "bu rakamları nereden biliyorsun" diye sorunca Fevzi Paşa ordu defterdarlarını kastederek "onun casusları var" dedi. Taarruz yaklaştı, ordu durmadan para istiyor, aşar vakti yakın, fakat zamanı gelmedi. Vergiler hep tahsil edilmişti, hiçbir yerde metelik bırakmamıştım. (Müderrisoğlu 2013: 413-414).

Bir gün Osmanlı Bankası'nın Ankara Şube Müdürü Bojeti'yi çağırttım ve ona dedim ki: "Osmanlı Bankası tarihi anını yaşıyor. Maliyeye bir buçuk milyon lira lazım.Bizim yönetimimiz altındaki bölgede on altı şubeniz var. İstediğim paraları vermezsen şubelerinizin hepsine el koyar, kaslarınızdaki bütün parayı tutanak karşılığ1 alırım. Düşünmen için sana on beş dakika veriyorum, git, düşün ve cevabını ver." Böylece istediğimiz parayı Osmanlı Bankası'ndan aldık. (Pulur 2005: 3).

Böylelikle bütün kaynaklar zorlanmış, 1922 yılının özellikle Mart ve Nisan aylarında birçok mali kanun çıkarılmıştı. Bu kanunlar subayların maddi durumunu düzeltmenin yanı sıra Türk ordusunun ihtiyaçlarının karşılanabilmesi için yeni gelirler sağlamayı amaçlamaktaydı. 6 Mayıs 1922'de çıkarılan Birinci Avans Kanunu ile 10 milyon, 3 Temmuz 1922'de çıkarılan İkinci Avans Kanunu ile 7 milyon ve 21 Ağustos 1922'de çıkarılan Üçüncü Avans Kanunu ile 5 milyon lira orduya harcanması amacıyla Millî Savunma Bakanlığına ödenek verilmiştir. Böylelikle Anadolu'nun bütün maddi kaynakları son kuruşuna kadar zorlanmıştır. Artık bu anlamda ne halkın ne de hükümetin yapacak hiçbir şeyi kalmamıştı. Eğer ordunun yapacağı taarruz başarıyla sonuçlanırsa Türk yurdu kurtulacak, aksi takdirde Millî Mücadele daha sıkıntılı bir süreçle karşı karşıya kalacaktı (Selek 2002: 1202-1206). 
Birinci TBMM'de çeşitli bakanlık görevlerinde bulunmuş olan Dr. Rıza Nur, hatıralarında Hasan Fehmi Bey ile ilgili çeşitli bilgilere yer vermiştir. Ona göre Hasan Fehmi Bey, sanki yüksek maliye okulundan mezun olmuşçasına mali meselelerde hayret edilecek düzeyde bilgi sahibiydi. Oysaki sadece Rüştiye mezunu olmasına rağmen kendinden önce maliye vekilliği görevinde bulunan Hasan (Saka) ve Şefik (Bekman) Beylerin yapamadığını yapmıştı. Dr. Rıza Nur, sözlerini şöyle devam ettirmiş̧ir:

Hasan Fehmi Bey, "j” harfini söyleyemezdi ve yazım-imlâ hatası yapmadan iki satır bile yazı yazamazdı. On satırlık bir müsveddesinde 20-25 yanlışı vardı. Fakat zeki, özellikle aklıselimi kuvvetli idi. Bunlarla bu mühim maddeleri hallediyor. Tam Türk, çelebi hususiyeti onda var. Zaten Pazarola Hasan (Saka) Maliye Vekili olur, işleri alt-üst ve çorba eder gider, Şaşı Hasan (Fehmi) gelir düzeltirdi. Vekâleti tıkır tıkır işletirdi. (Nur 1967: 1169-1170).

\section{Lozan Konferansı Görüşmeleri}

Büyük Taarruz ile Yunan işgaline son verilmiş ve bu durum Mudanya Mütarekesi ile teyit edilmişti. Ancak nihai antlaşma 20 Kasım 1922'de İsviçre'nin Lozan kentinde toplanan barış görüşmeleri sonunda imzalanacaktı. Lozan Konferansı'nın 23 Nisan 1923 'te başlayan ikinci döneminde kuponlar ve maddi imtiyazlar meselesi gündeme geldiğinde, Türk Temsilci Heyeti Başkanı İsmet Paşa ile Ankara'da bulunan Türk Hükümeti özellikle Başvekil Rauf Bey arasındaki ilişkiler gerginleşmeye başlamıştı. İsmet Paşa'nın 25 Haziran 1923'te Ankara'ya gönderdiği telgrafta, konferanstaki Türk heyetinin atacağı her adımın hükümet tarafından idare edilme istek ve eğiliminden rahatsızlık duyduğunu bildirmekteydi. İsmet Paşa'ya göre bu hareket tarzı; konferans görüşmelerinin Türkiye açısından en yararlı bir şekilde idaresi ve hayırlı bir barışa ulaşma gücünü Türk heyetinin elinden almaktaydı. Hükümetin böyle davranmasını, adeta 93 Harbi'nin saraydan yönetilmesine benzeten İsmet Paşa, kendisine karşı güvensizlik duyulup ve yetersiz olduğu hissedildiği takdirde konferansta bulunan heyetin başarılı olamayacağı fikrinde idi. Bu düşüncelere sahip olan İsmet Paşa, kendisini eleştiren hükümete, özellikle de Hasan Fehmi Bey’e yönelttiği şu tavsiye ile telgrafını bitirmişti: "Hükümetin görüşlerini, İtilaf Devletlerine olduğu gibi kabul ettirebileceğine inanan bir heyetin, özellikle Maliye Bakanı Beyefendinin doğrudan doğruya sorumluluk yüklenerek konferansa gelmelerini rica ediyoruz". (Atatürk 1994: 530-531, Orbay 1993: 119, Şimşir 1994: 491-492).

\section{E. Cumhuriyet Dönemi'nde TBMM'deki Faaliyetleri}

Hasan Fehmi Ataç Türkiye Büyük Millet Meclisinde, 1920 yılından itibaren sekiz dönem boyunca milletvekilliği yapmıştır (TBMM Arşivi, Sicil Dosya No: 187). 14 Kasım 1934'te toplanan Cumhuriyet Halk Fırkası grubunda İsmet Paşa, Türkiye Büyük Millet 
Meclisinin anayasaya göre 1935 yazında seçim kararı alması gerektiğini ancak uluslararası durumun seçimin yenilenmesini zorunlu kıldığından, seçimin öne alınmasının, böylece Cumhuriyet Halk Fırkasının ve hükümetin durumunun millet oyuyla yeniden belirlenmesinin yararlı olacağını belirtmişti (Güneş 2004: 1). Bunun üzerine 5 Şubat 1935 'te milletvekili aday listeleri açıklanmış ve Hasan Fehmi Bey, Cumhuriyet Halk Fırkasının Gümüşhane’den aday gösterilmişti (Cumhuriyet, 5 Şubat 1935: 3).

8 Şubat 1935 sabahı başlayan seçimler, aynı gün akşamına kadar yurdun her tarafında tamamlanmış ve 399 milletvekilinden 17'si kadın olmak üzere 386 milletvekili Cumhuriyet Halk Partisi adaylarından 13'ü de bağımsızlardan seçilmişti. Hasan Fehmi Bey de Gümüşhane'yi TBMM'de temsil etme yetkisini bir kez daha elde etmişti (Cumhuriyet, 9 Şubat 1935: 5). V. Dönem Türkiye Büyük Millet Meclisi 1 Mart 1935'te açılmış, ilk önce milletvekillerinin yemin töreni gerçekleşmiş, ardından Mustafa Abdülhalik Renda'nın Meclis Başkanlığına, ondan sonra da Kemal Atatürk'ün Cumhurbaşkanlığına dördüncü kez seçilmesi gerçekleşmiş ve 7 Mart 1935'te toplanmak üzere meclis oturumu sona ermişti (TBMM ZC V/I-I: 1-7). 7 Mart 1935'te Hasan Saka'nın başkanlığında toplanan meclisin birinci celsesinde, seçilen milletvekillerinin isimleri tek tek ve alfabetik sıraya göre okunarak mazbataları onaylanmıştı. Mazbataların onaylanmasının ardından encümenler için seçim yapılmış ve Gümüşhane Milletvekili Hasan Fehmi Ataç, Maliye Encümeni'ne seçilmişti (TBMM ZC V/I-2: 26). Atatürk'ün 10 Kasım 1938'de vefat etmesiyle İsmet İnönü Cumhurbaşkanlığına seçilmişti. Türkiye Cumhuriyeti tarihinde 1938-1945 yılları arasındaki bu yeni dönem, Millî Şef Dönemi olarak adlandırılmıştı. V. Dönem TBMM, 27 Ocak 1939 tarihinde çalışmalarını tamamlayarak seçime gitme kararı almıştı (TBMM ZC V/XXIX-28: 220-221; Resmî Gazete 7 Şubat 1939: 11253). 25 Mart 1939 tarihli gazetelerde milletvekili aday listeleri açıklanmış, bu listelere göre Hasan Fehmi Ataç yine Gümüşhane'den milletvekili adayı gösterilmişti.

Adayların ilan edilmesinden sonra seçimler, 26 Mart 1939'da tüm yurtta gerçekleşmişti. Seçim sonunda meclise 15'i kadın olmak üzere 424 milletvekili girmişti. (Binark 2004: 61) 3 Nisan 1939'da TBMM'nin açılmasının ardından 10 Nisan 1939'da da encümen seçimine gidilmiş ve Hasan Fehmi Ataç bu yeni dönemde ise Milli Müdafaa Encümenliğine seçilmiştir. (TBMM ZC VI/I-2: 19) Hasan Fehmi Bey'in bu dönemde TBMM'de 1 teklifi ve 35 konuşması vardır.

Atatürk Dönemi olarak adlandırılan 1923-1938 yılları arasında Türkiye Cumhuriyeti, her anlamda büyük atılımlar yapmıştı. Özellikle yaklaştığı hissedilen II. Dünya Savaşı'na karşı önlem olarak Türk ordusunun güçlendirilmesine öncelik 
verilmişti. Yabancı şirketlerin elinde bulunan birçok işletme satın alınarak millileştirilmiş, yeni sanayi atılımları yapılmış, eğitim ve sağlık alanında büyük gelişmeler sağlanmıştı. Bu yatırımlar borçlanma yoluna gidilmeden, denk bütçe ve milli kaynaklarla yapılmıştı. Geçmiş yıllarda ithal edilen birçok ürün Türkiye’de üretilmeye başlanmış, bu gelişmelerin yanı sıra her yıl 5 milyon altın Osmanlı borcu da ödenmişti. "Kambiyo kelimesinin anlamını Başbakan olduktan sonra öğrendim” diyen İsmet İnönü, hiçbir diploması olmayan İktisat Bakanı ve Başbakan Celal Bayar, hiç yüksek tahsil görmemiş Maliye Bakanı Hasan Fehmi Ataç ve hiçbir ekonomi eğitimi almayan M. Kemal Atatürk önderliğindeki Türkiye Cumhuriyeti’nin 1923-1938 y1lları arası dönemde karşılıksız hiç dış borç alınmadan " 0 ” enflasyonla Cumhuriyet tarihimizin en yüksek kalkınma hızı olan \%9'a ulaşması ancak bu kişilerin yurtseverliği ile açıklanabilir (Kal 2016: 110-115).

Hasan Fehmi Ataç, ikisi Osmanlı Mebusan Meclisinde ve sekizi de Türkiye Büyük Millet Meclisinde olmak üzere toplam on dönem Gümüşhane milletvekilliği yaptıktan sonra 1961 y1lında vefat etmiştir. Kendisi bugün, Türkiye Cumhuriyeti'nin ilk maliye bakanı olarak hatırlanmaktadır. Kırmızı şeritli İstiklâl Madalyasına sahip olan Hasan Fehmi Bey'in ismi bugün Gümüşhane'de ailesine ait ve kendi adı ile anılan konakta yaşamaktadır (BCA 30.10.0.0/195.335.10: 1-3; Günaydın: 35-36; Özkan vd: 84$85)$.

\section{Sonuç}

Hasan Fehmi Ataç, tarihi bakımından Osmanlı Devleti'ne çeşitli hizmetlerde bulunmuş Gümüşhane'de oldukça köklü bir aileye mensuptur. Türk parlamento Tarihi'nde en uzun süre milletvekilliyi yapan tarihi şahsiyetlerden biridir. Hasan Fehmi Ataç, Meclis-i Mebusan'ın kapanmasının ardından Anadolu'ya geçerek Milli Mücadeleye katılmıştır. Ankara'da TBMM'nin açılmasıyla birlikte bu yeni meclise dâhil olup, Türk milletinin bağımsızlığı için mücadele etmeye devam etmiştir. Osmanlı' dan Cumhuriyet'e, tek parti döneminin sonuna kadar uzanan bir siyasi hayatı olmuştur. $\mathrm{Bu}$ süre zarfında Maliye ve Tarım Bakanlığg yapmış, ayrıca II. ve I. Başkan Vekilliği’nde de bulunmuştur.

Hasan Fehmi Ataç'ın Türk siyasi hayatında unutulmaz izler bırakan dönemi, kuşkusuz Maliye Bakanı olduğu yıllardır. Millî Mücadele Dönemi’nde Büyük Taarruz öncesi Türk ordusunun hazırlanması ve gerekli olan maddi ihtiyaçlarını karşılaması hususunda çok büyük yararlılıklar göstermiştir. Hiçbir ekonomi eğitimi almamasına rağmen ekonomik problemlere kendine has yöntemlerle çare bulduğu görülmektedir. Ülkenin gelirlerinin yetmediği en zor günlerinde, oldukça disiplinli bir çalışma anlayışına 
sahip olduğundan, olağanüstü dönemlerde olağanüstü kararlar alarak, başta ordu olmak üzere kurumların maddi ihtiyaçlarını karşılayabilmiştir. Ordu personellerinin düzenli maaş almalarını sağlamak suretiyle de o dönemde bir ilki başarmıştır. Bu başarıları sayesinde Türkiye Cumhuriyeti'nin ilk maliye bakanı olmuştur. Memleketi olan Gümüşhane'de ailesinden kalan ve kendi adıyla anılan konakta bugün adı ve hatırası halen yaşamaktadır.

\section{Kaynakça}

\section{Arşivler}

Başbakanlık Cumhuriyet Arşivi

TBMM Arşivi

\section{Resmi Yayın ve Zabıtlar}

TBMM Gizli Celse Zabıtları, Devre: I, Cilt: I, İçtima: 1

TBMM Zabıt Ceridesi, Devre: V, Cilt: I, İçtima: 1

TBMM ZC, Devre: V, Cilt: I, İçtima: 2

TBMM ZC, Devre: V, Cilt: 29, İçtima: 28

TBMM ZC, Devre: VI, Cilt: 1, İçtima: 2

\section{Süreli Yayınlar}

Cumhuriyet

\section{Kitap ve Makaleler}

ATATÜRK, Mustafa Kemal (1994). Nutuk 1919-1927, Ankara: Atatürk Araştırma Merkezi Yayını.

BİNARK, İsmet (2004). Türk Parlamento Tarihi TBMM VI. Dönem (3 Nisan 1939-15 Ocak 1943) (I), Ankara: TBMM Vakfi Yayınları No. 36.

ÇETIN, M; GÜRSOY, A.; BULGUR, İ.; TÜRE, A.; DEMIREL K.; ÇIÇEK, P. (1997). Sayılarla Gümüşhane, İstanbul: Gümüşhane Valiliği Yayınları No: 2.

ÇOKER, Fahri (1995). Türk Parlamento Tarihi 1919-1923 (III), Ankara: TBMM Vakfi Yay. No. 6.

DABAĞ, Sevim (2019). İstiklal Savaşı'nın Mali Kahramanı: Hasan Fehmi Ataç, İstanbul: Tarihçi Kitabevi. 
Mustafa ÖZYÜREK, “Türkiye Cumhuriyeti’nin İlk Maliye Bakanı Gümüşhane Milletvekili Hasan Fehmi Ataç'ın Mali Alandaki Faaliyetleri”, Mavi Atlas, 7(2)/2019: 265-274

DEMIREL, Ahmet (2003). Birinci Meclis'te Muhalefet İkinci Grup, İstanbul: İletişim Yayınları.

GÜMÜŞHANE VALİLİĞİ (1974). Cumhuriyetin 50. Yılında Gümüşhane 1973 İl Yıllı $\breve{g l}$, Ankara: Ayyıldız Matbaası.

GÜNEŞ, İhsan (2004). Türk Parlamento Tarihi (1935-1939) I, Ankara: TBMM Vakfı Yayınları.

KAL, Nazmi (2016). “Ekonomi Tarihi, Dünya Ekonomisine Atatürk’ün getirdiği Yeni Kavram: Devletçilik-Karma Ekonomi”, Ekonomik Forum, İstanbul: TOBB Yayınları.

KONUKÇU Enver, “Milli Mücadele'de Erzurum (1918-1923)”, Şehr-i Mübarek Erzurum, Ankara: Erzurum Belediyesi Kültür Yayınları, Ankara, 1989, s. 124-137

MÜDERRİSOĞLU, Alptekin (2013). Kurtuluş Savaşı'nın Mali Kaynakları, Ankara: Atatürk Araştırma Merkezi Yayınları.

NUR, Rıza (1967). Hayat ve Hatıratım III, İstanbul: Altındağ Yayınevi.

ORBAY, Rauf (1993). Cehennem Değirmeni Siyasi Hatıralarım II, İstanbul: Emre Yayınları.

ÖZKAN, H.; YURTTAŞ, H. (2012). Orta Çă̆’dan Günümüze Gümüşhane, Gümüşhane: Seçil Ofset.

PULUR, Hasan (13 Nisan 2005). "Maliye'den Anlamayan Bir Maliye Bakanı", Milliyet, 3.

SELEK, Sabahattin (1987). Anadolu Ihtilali I, İstanbul: Kastaş Yayınları.

SELEK, Sabahattin (2002). Milli Mücadele (Ulusal Kurtuluş Savaşı) II, İstanbul: Örgün Yayınevi.

ŞİMŞİR, Bilâl N. (1994). Lozan Telgrafları II (Şubat-A ğustos 1923), Ankara: Türk Tarih Kurumu Yayınları. 